\title{
Implicaciones de la nueva ley de financiación de la agrupación Radio Televisión Española (RTVE)
}

\author{
David CAldevilla Domínguez \\ Universidad Complutense de Madrid \\ davidcaldevilla@ccinf.ucm.es
}

Recibido: 14 de marzo de 2012

Aceptado: 15 de octubre de 2012

\begin{abstract}
Resumen
La nueva Ley de Financiación de la Corporación Radio Televisión Española ha resultado polémica desde su anuncio el 3 de mayo de 2009 por la entonces Vicepresidenta María Teresa Fernández De la Vega. La nueva ley es la respuesta a años de críticas por parte de los operadores de televisión privada y supone la adecuación a las directrices europeas del sector. La nueva legislación supone un punto de inflexión en la historia de RTVE, con una transformación de un sistema mixto de financiación publicitaria e institucional, a uno carente de publicidad, en consonancia con las otras naciones europeas occidentales.
\end{abstract}

Palabras clave: Financiación Televisiva, Televisión, Ley Audiovisual, Anuncios, Publicidad.

\section{Implications of the new law of financing of the group Radio Televisión Española (RTVE)}

\begin{abstract}
The new Financing Law of the Spanish Radio and Television Corporation has proved controversial since its announcement by Vice President Maria Teresa Fernandez de la Vega. The new law is a response to years of criticism from private television operators and requires the matching of European directives in the sector. The new legislation represents a watershed in the history of RTVE, with a transformation of a mixed system of an institutional and advertising financing, to one without any advertising, in line with other Western European nations, which has been well received by their public.
\end{abstract}

Keywords: Financing Television, TV, Audiovisual Law, Spots, Advertising.

Referencia normalizada: CALDEVILLA DOMÍNGUEZ, David (2012): "Implicaciones de la nueva ley de financiación de la agrupación Radio Televisión Española (RTVE)". Estudios sobre el mensaje periodístico, vol. 18, núm. 2 (julio-diciembre), págs.: 661-677. Madrid, Servicio de Publicaciones de la Universidad Complutense.

Sumario: 1. Introducción. 2. Contexto de la ley: situación de RTVE antes de la entrada en vigor de la ley; 2.1 Breve historia de las televisiones en España; 2.1.1 La aparición de Televisión Española; 2.1.2. Aparición de las televisiones autonómicas; 2.1.3. Surgimiento de las cadenas privadas; 2.1.4. La Televisión Digital Terrestre. 3. Leyes europeas de la televisión pública y Derecho comparado; 3.1. Gran Bretaña: El canon y la BBC; 3.2. Alemania: Sin publicidad en máxima audiencia; 3.3. Italia: Cantidad de anuncios limitada;. 3.4. Portugal: Sistema similar al español; 3.5. Francia: Cambio radical. 4. La ley en España. 5. Reacciones a la ley. 6. Conclusiones.7. Referencias bibliográficas.

\section{Introducción}

El 3 de mayo de 2009, la vicepresidenta primera del Gobierno, María Teresa Fernández De la Vega, anunció a los directivos de Televisión Española que pretendía eliminar la publicidad en las dos cadenas públicas estatales mediante una nueva ley que entraría en vigor a partir del mes de septiembre, "si los plazos parlamentarios se cumplían con rapidez". Finalmente, el 31 de agosto se publicó esta nueva ley que entró en vigor al día siguiente, lo que suponía un indudable punto de inflexión en el panorama audiovisual español al modificar de manera sustancial la financiación del Ente Público. 
De esta manera, se satisfacía una demanda histórica de las televisiones privadas, cuyos directivos y portavoces habían elevado el tono de las críticas hacia RTVE desde el comienzo de la crisis económica. En este artículo tratamos de esclarecer en qué medida pueden afectar estos cambios importantes al desarrollo de la televisión pública en nuestro país, valorando la posibilidad de que la ausencia de publicidad suponga una pérdida importante de calidad en los contenidos o que, por el contrario, permita el normal funcionamiento de la cadena dependiente de los impuestos de los ciudadanos españoles.

Acotaremos el contexto en el que se ha promovido esta ley, encuadrándola dentro de las medidas requeridas dentro de las disposiciones establecidas en el Protocolo 32 del Tratado de Constitución de la Comunidad Europea sobre el sistema de radiodifusión de los Estados miembros. Además, realizaremos un ejercicio comparativo de la regulación audiovisual a nivel europeo ya que una sinopsis de la situación ayudará a comprender mejor el futuro. Asimismo, distinguiremos y estudiaremos el significado de los puntos más polémicos de la ley, analizando las reacciones que ha suscitado en los públicos de Televisión Española.

\section{Contexto de la ley: situación de RTVE antes de la entrada en vigor de la ley 2.1. Breve historia de las televisiones en España}

\subsubsection{La aparición de Televisión Española}

Televisión Española comienza sus emisiones con una misa el 28 de octubre de 1956, realizando las primeras emisiones desde un reducido plató de unos cien metros cuadrados en el madrileño Paseo de la Habana y llegando únicamente la señal a los televisores de dicha ciudad.

Es en la década de los 60 cuando el alcance de la señal empieza a considerarse masivo, aunque todavía no había alcanzado el grado de implantación que adquiriría a lo largo de los años. Hecho que sucede gracias a que los poderes públicos potencian políticas para incentivar el consumo televisivo y aumentar la penetración del medio en la sociedad española. Así, fue decisiva la anulación del impuesto de lujo en la compra de los aparatos receptores o la posibilidad del pago a plazos de los televisores.

A partir de la segunda mitad de la década, se puede hablar de un boom de Televisión Española, que se ha transformado ya en una empresa que genera pingües beneficios y que tiene capacidad de producción para elaborar programas competitivos en el contexto de los festivales europeos. Probablemente, el salto no solamente cuantitativo, sino con total seguridad cualitativo, sobrevino por la utilización de la publicidad como fuente de ingresos. La recaudación por los anuncios emitidos permite que se aumente el presupuesto para la creación de nuevos contenidos, la aparición de un segundo canal de Televisión Española en 1965 (TVE 2) y la compra de los estudios de Prado del Rey, en Pozuelo de Alarcón, pueblo dormitorio de la ciudad capital. En el resto de los países europeos el uso de la publicidad en televisión se encontraba prohibido o muy restringido.

La actividad televisiva en España siguió desarrollándose en forma de actividad monopolística por parte del Estado durante las últimas décadas del franquismo y los 
primeros años de la democracia, quedando al albur de los designios del gobierno de turno, tal y como sucedía en la dictadura de Francisco Franco.

\subsubsection{Aparición de las televisiones autonómicas}

En la década de los 80, la opinión pública española comenzaba a demandar la existencia de una tercera cadena que satisficiera los intereses de los telespectadores, del mismo modo que estaba ocurriendo en otros países de nuestro entorno, como Francia e Italia, desde la segunda mitad de los 70. Ante la incapacidad por parte de TVE de dar respuesta a estos requerimientos por parte de la audiencia, el Congreso de los Diputados aprobó en diciembre de 1983 la Ley de los terceros canales de televisión, otorgándoles a las Comunidades Autónomas la potestad para la emisión de un nuevo canal de titularidad pública. Así comenzaron a surgir a lo largo de los años 80 una serie de canales que se agruparon bajo el nombre de la FORTA: Federación de Organismos de Radio y Televisión Autonómicos. Euskal Telebista (ETB), Televisió de Catalunya 3 (TV3), Televisión de Galicia (TVG), Canal Sur de Andalucía, TeleMadrid, Canal 9 de Valencia. Presentándose ya en los años 90 los canales autonómicos de las Islas Canarias, (TVC) y de Castilla la Mancha (CCM), además de una segunda generación de canales autonómicos de las emisoras de "primera generación" (ETB2 en el País Vasco, Canal 33 en Cataluña, Punt 2 en la Comunidad Valenciana, La Otra en Madrid, Canal Andalucía 2 en Andalucía). En 2003 emite Teleprincipado en Asturias y desde 2006 Tele Aragón.

Caso aparte, por lo peculiar, supone el Canal 10 (Film Succes S.A.). Canal 10 fue el primer canal de televisión privado en España. Su programación se basaba en películas, series, teleseries, programas de entretenimiento y música, todos ellos de calidad y sin cortes. Una especie de precursor del tipo de programación de Canal Plus, años después. Fue la primera emisora española que no emitía anuncios y no interrumpía las películas. Primero emitió dos meses de forma gratuita y luego pasó a ser un canal de pago. Sus emisiones empezaron en enero de 1988 y finalizaron en septiembre del mismo año. El canal llegó a los 654 abonados a 3.500 pesetas $(21,03 €)$ mensuales de cuota más 15.000 pesetas iniciales $(90,15 €)$ como derecho de conexión.

La falta de una ley concisa en emisiones televisivas privadas hizo que José María Calviño (ex-presidente de RTVE y último director con el que el Ente obtuvo beneficios de mención) impulsara este canal, amparándose en un vacío legal que permitía emitir sin vulnerar el espacio radioeléctrico de titularidad estatal. Se emitía desde Londres a través del satélite Intelsat-5, que en aquel entonces era una de las pocas compañías con emisiones por satélite, con cobertura para España. Esta circunstancia se aprovechaba de uno de los flecos legales que no contemplaba la emisión desde fuera de España vía satélite. Canal 10, para aumentar abonados y presencia entre el público, pactó con diversos vídeos comunitarios (pequeñas redes locales de televisión de pago) la remisión de ciertos programas del canal.

Canal 10 comenzó sus emisiones el 25 de enero de 1988 de forma experimental, continuando de forma regular al día siguiente con la emisión de la película 'Kramer contra Kramer' sin anuncios por primera vez en España. 
La emisión era gratuita hasta marzo y no se requería más que un receptor analógico de satélite y una parabólica orientada a $1^{\circ}$ Oeste. La emisión pasó al sistema de pago el 6 de marzo del mismo año. Entonces la cadena empezó un relanzamiento de la marca, publicitándose en equipos deportivos (ciclismo) o incluso contratando una actriz hollywoodiense como Bo Derek (en clara relación con su película más famosa, '10, la mujer perfecta') para los anuncios de la cadena. Sólo era posible darse de alta en grandes ciudades (Madrid, Barcelona, Valencia), ya que sólo en ellas Canal 10 efectuaba las instalaciones gratuitas de la parabólica y el receptor. El 12 de octubre se presenta una definitiva suspensión de pagos.

\subsubsection{Surgimiento de las cadenas privadas}

En diciembre de 1989 y en marzo de 1990 respectivamente, comienzan sus emisiones Antena 3 y Telecinco, dos televisiones privadas de cobertura nacional. También en 1990 nace en España el modelo de televisión de pago por medio de Canal Plus, cadena codificada en su contenido sustancial pero de concepción estatal y generalista como las otras dos televisiones privadas recién creadas. Posteriormente, surgirían paquetes de canales de pago como Canal Satelite Digital, Vía Digital, cuya fusión dio lugar a Digital Plus, o Imagenio. Ya en el siglo XXI el Gobierno otorgó otras dos licencias de titularidad privada para emitir en abierto. Estas últimas propuestas televisivas de carácter generalista fueron impulsadas por el grupo Sogecable, dueño de Canal + (canal eminentemente codificado), quien pidió al Gobierno español un cambio legal que le permitiera emitir de manera abierta (no codificada). Esta petición tuvo respuesta positiva en julio de 2005, aunque Canal + decidió crear un nuevo canal generalista: Cuatro. En el mismo Consejo de ministros se convocó un concurso para un nuevo canal de televisión nacional, generalista y analógico, que se adjudicó en diciembre del 2005 a la compañía Gestora de Inversiones Audiovisuales La Sexta, próxima al Presidente Zapatero según la oposición, que opera desde entonces bajo el nombre comercial de La Sexta.

\subsubsection{La Televisión Digital Terrestre}

En 2002 y de la mano de Quiero TV aparece en España la Televisión Digital Terrestre. A pesar de que dicha cadena no logra alcanzar el éxito previsto y se ve abocada a su desaparición, la TDT va progresando en España, especialmente desde la adquisición por parte de La Sexta de los derechos de retransmisión del Mundial de Alemania 2006, debido a la escasa calidad de la señal en analógico de dicha cadena.

Los grupos televisivos adquieren licencias para emitir mediante tres o cuatro canales en formato digital y la implantación de este formato avanza durante el segundo lustro de la primera década del nuevo siglo, hasta llegar al apagón analógico, que ocurrirá en todo el territorio nacional el 3 de abril de 2010.

Además, observamos que de los tres principales operadores televisivos españoles, TVE, Antena 3 y Telecinco, esta última es la que presenta una tasa de variación menos negativa, siempre según el Informe de la CMT. 


\begin{tabular}{|c|c|c|c|}
\hline \multicolumn{4}{|c|}{$\begin{array}{c}\text { INVERSIÓN ESTIMADA en publicidad EN MEDIOS CONVENCIONALES } \\
\text { 2007-2008 y tasa de variación POR OPERADOR } \\
\text { (millones de euros y porcentaje) }\end{array}$} \\
\hline & 2008 & 2007 & $2008-2007$ \\
\hline TOTAL & $2.988,1$ & $3.357,6$ & $-11,00 \%$ \\
\hline TVE & 596,8 & 716,5 & $-16,70 \%$ \\
\hline Telecinco & 919,5 & $1.036,8$ & $-11,30 \%$ \\
\hline Antena 3 & 685,4 & 834,8 & $-17,90 \%$ \\
\hline Cuatro & 301,8 & 281,9 & $7,10 \%$ \\
\hline La Sexta & 165 & 132,8 & $24,00 \%$ \\
\hline Total Televisiones Nacionales & $2.668,5$ & $3.002,8$ & $-11,10 \%$ \\
\hline TV. Aut. Canaria & 4,8 & 5,3 & $-10,10 \%$ \\
\hline TV3 & 118 & 132 & $-10,50 \%$ \\
\hline TV Galicia & 24,2 & 25,9 & $-6,80 \%$ \\
\hline E.T.B & 23,8 & 22 & $8,50 \%$ \\
\hline TV. M & 45,1 & 55 & $-18,00 \%$ \\
\hline Canal Sur & 48,1 & 55 & $-12,50 \%$ \\
\hline Canal 9 & 28,4 & 34 & $-16,50 \%$ \\
\hline TV CMT & 3,8 & 4,8 & $-20,70 \%$ \\
\hline IB 3 & 7,5 & 6,8 & $10,20 \%$ \\
\hline TPA & 1,5 & 1,3 & $18,70 \%$ \\
\hline TV. Aragón & 2,6 & 2,3 & $15,10 \%$ \\
\hline TAM & 2,7 & 2,8 & $-5,10 \%$ \\
\hline $8 \mathrm{TV}$ & 6,5 & 5,8 & $12,10 \%$ \\
\hline Onda 6 & 2,6 & 1,9 & $40,00 \%$ \\
\hline Total Televisiones Autonómicas & 319,6 & 354,7 & $-9,90 \%$ \\
\hline
\end{tabular}

Datos estimados por InfoAdex.

Fuente: Estudio Infoadex de la inversión publicitaria en España 2009

Podríamos llegar a colegir que Telecinco ha recrudecido sus críticas a la financiación mixta de TVE en previsión a un posible mal ejercicio económico durante 2009, pero de ser así, no parecería muy oportuno que el pasado 30 de julio Telecinco expusiera sus cuentas del primer semestre del año y se vanagloriara de "ser el medio de comunicación" más rentable, alcanzando un beneficio neto de 62,5 millones de euros. En el ejercicio completo del 2009, aún no publicado, se esperan también altos lucros finales.

Las reprobaciones que las cadenas privadas hacen sobre el esquema de la financiación de la televisión de titularidad estatal son realizadas por comparación a la situación de las televisiones públicas en otros países, tradicionalmente con la paradigmática British Broadcasting Corporation (BBC) británica. Las grandes corporaciones televisivas encontraron otro ejemplo cuando Nicolás Sarkozy anunciaba que la televisión pública francesa suprimiría la publicidad desde el 1 de enero de 2009. 


\section{Leyes Europeas de la televisión pública y Derecho comparado}

Debemos centrar nuestro análisis en conocer como se encuentra el sector de la televisión pública en la Unión Europea y cuáles son las disposiciones acordadas por parte de las altas instancias europeas en esta materia para poder valorar las repercusiones de su aplicación.

Para comenzar con las disposiciones de la Unión Europea sobre la financiación de las televisiones públicas debemos remontarnos al Protocolo de Amsterdam o Protocolo 32, adjunto al Tratado de Maastricht (Holanda) y que expone lo siguiente:

"Las disposiciones del Tratado constitutivo de la Comunidad Europea se entenderán sin perjuicio de la facultad de los Estados miembros de financiar el servicio público de radiodifusión en la medida en que la financiación se conceda a los organismos de radiodifusión para llevar a cabo la función de servicio público tal como haya sido atribuida, definida y organizada por cada Estado miembro, y en la medida en que dicha financiación no afecte a las condiciones del comercio y de la competencia en la Comunidad en un grado que sea contrario al interés común, debiendo tenerse en cuenta la realización de la función de dicho servicio público".

En el protocolo se le otorga a los Estados miembros de la Unión la potestad de determinar las funciones de financiación y servicio público, que se verá únicamente limitada por su nivel de incidencia en el comercio y en la libre competencia. Aquí subyace la idea de que, lógicamente, si no se realiza ninguna reclamación ante los distintos órganos reguladores de la competencia, la Unión Europea no intervendrá ante los distintos Estados en lo referente a los asuntos de radiodifusión.

En 1992 y 1994, las cadenas privadas Telecinco y Antena 3 presentaron sus reivindicaciones acerca de una posible competencia desleal de RTVE por su estructura de doble financiación. La Comisión Europea guardó silencio por el momento, pero en 1998 una sentencia del Tribunal de Justicia de Primera Instancia exigió su resolución. En 1999, se remitió un requerimiento a España solicitando la información necesaria para evaluar las ayudas. El asunto recayó en manos del Comisario de la Competencia, Mario Monti, quien se pronunció al respecto y amenazó con expedientar a RTVE, en caso de que no modificara su actividad publicitaria. Concluyó que los subsidios que recibe RTVE respondían al servicio público que presta, pero no ha lugar para que el Estado garantice la deuda del ente radiotelevisivo.

El mismo expediente exigía a la televisión pública italiana RAI diferenciar su contabilidad entre la actividad comercial y pública, tras una denuncia del grupo Mediaset ligado a Silvio Berlusconi, dueño de la cadena Telecinco italiana. También exigía al gobierno portugués la justificación de las ingentes ayudas que otorga a la Rádio Televisão Portuguesa (RTP).

Esta sucesión de hechos que han ido marcando la situación a nivel europeo en el sector de la financiación pública audiovisual, presenta otro punto de inflexión en el año 2001, cuando la Comisión redacta una Comunicación en la que se cataloga la televisión dentro del ámbito de los servicios de interés público, cuyo objetivo es "reconocer la plusvalía de los servicios de interés general en la realización de un mercado interior accesible a todos y definir el campo y criterios de aplicación de las normas de competencia en este ámbito". 
Su inclusión dentro de los servicios de interés público general conlleva que deban cumplir una serie de características, como bien enunció Enrique Bustamante, profesor de la Universidad Complutense de Madrid y miembro del Comité de Sabios al que el Gobierno de José Luis Rodríguez Zapatero encomendó la creación de un informe al respecto. Tales características son:

- Definición y encargo legal del servicio público

- Supervisión por Autoridad independiente

- Proporcionalidad (dinero público con costes netos sin publicidad.)

- Transparencia (contabilidad analítica)

Otro mojón indispensable en este camino se produce en el año 2005, cuando el Consejo dio a conocer su Informe para la reforma de RTVE. En él realizaba una serie de críticas a la corporación:

- Estatuto obsoleto

- Definición insuficiente del servicio público

- Gestión gubernamentalizada

- Modelo financiero inviable:

- Subvención pública minúscula

- Endeudamiento oneroso

- Influencia de la publicidad excesiva

- Contabilidad opaca

- SEPI contraproducente

- Insuficiencias digitales

El hecho de que el modelo financiero de RTVE fuera considerado por parte del Consejo Europeo como inviable, supuso una perfecta excusa para que desde las cadenas de titularidad privada se criticara de manera vehemente el panorama mediático en España.

La controversia se avivó en España cuando desde el Gobierno de Francia se informó de su intención de eliminar la publicidad de los canales de titularidad pública. El pasado 3 de mayo de 2009, al hilo de lo sucedido en Francia, la número dos del Gobierno, María Teresa Fernández De la Vega, hacía público oficialmente que les había hecho saber a los directivos de Televisión Española su intención de eliminar la publicidad en las cadenas de la Corporación a partir del mes de septiembre, caso de que los plazos parlamentarios se cumplieran con eficacia, como hemos comentado anteriormente.

Desde la Unión Europea se proclamó que se iba a incoar una investigación para comprobar que la nueva Ley de Financiación de RTVE cumplía con la legalidad vigente comunitaria. La Vicepresidenta Primera de Gobierno se reunió en Estrasburgo el pasado 14 de septiembre con Neelie Kroes, Comisaria de Competencia de la Unión Europea, en una cumbre, recogida por medios escritos como El Mundo, en la que la mandataria española calificó la nueva ley de: "totalmente compatible con los tratados europeos" vanagloriándose de que "era el momento para acometer esta nueva regulación" y de que "el modelo español se basa en principios aún más estrictos que los establecidos por la Comisión Europea" 
Para entender sus palabras hemos de remitirnos a un estudio comparado de las diversas realidades legales positivadas en los distintos países que componen la Comunidad Económica Europea y que están sometidos a la misma legislación común expuesta en el Protocolo 32.

\subsection{Gran Bretaña: el canon y la BBC}

La prestigiosa televisión estatal británica, la British Broadcasting Corporation (BBC), se financia a través de un canon obligatorio, ya que tiene prohibida la emisión de publicidad. Este canon se aplica por la tenencia de televisor, así el Ministerio de Cultura, Medios de Comunicación y Deporte determina el precio que los poseedores de un televisor deben pagar. Desde 1986 el Gobierno decidió que el precio del canon iría unido al crecimiento del IPC. Actualmente, el coste de este impuesto directo es de unos 175,50 euros anuales por familia. Cabe señalar que existe un canal público que se financia con publicidad, Channel 4 , organismo sin ánimo de lucro, que tiene establecido un límite máximo legal de 12 minutos por hora de emisión.

\subsection{Alemania: sin publicidad en máxima audiencia}

Los dos entes audiovisuales públicos alemanes, la Zweites Deutsches Fernsehen (ZDF) y la Arbeitsgemeinschaft der öffentlich-rechtlichen Rundfunkanstalten der Bundesrepublik Deutschland (ARD), (corporación de 10 cadenas, parecido al sistema de televisiones autonómicas español), tienen implantado por ley un promedio anual de 20 minutos diarios de publicidad. Además, los anuncios están prohibidos a partir de las ocho de la noche y, también, los domingos y los días festivos. Existen dos canales, ARD-3 y Kinder Kanal, que no emiten anuncios. El canon por el cual se subvencionan estos canales tiene un valor cercano a los 200 euros anuales por hogar.

\subsection{Italia: cantidad de anuncios limitada}

La normativa que rige la televisión pública italiana, la Radio Televisione Italiana (RAI), marca el máximo establecido en Europa: 12 minutos de publicidad por hora de emisión. Además, está permitido superar este máximo en un $2 \%$, siempre y cuando la cantidad de publicidad se vea recortada en la hora siguiente. La financiación de RAI Uno y RAI Due se reparte entre un canon (que cubre el 50\%), un convenio con el Estado (3\%), la publicidad directa (44\%) y otras fórmulas (3\%), como puede ser la venta de programas. El canon se sitúa en unos 92 euros anuales por familia.

\subsection{Portugal: sistema similar al español}

Los dos canales de la televisión pública portuguesa, la Rádio Televisão de Portugal RTP, disfrutan de un sistema de financiación mixto, similar al español. Es decir, tanto la RTP-1 como la RTP-2 tienen cubierto el 50\% de su presupuesto anual con la subvención directa del Estado, y el otro 50\% con los anuncios publicitarios que emite. El único óbice es que la publicidad sólo se permite en la primera cadena pública, con el límite de 7,5 minutos por hora de emisión. No existe un canon anual. 


\subsection{Francia: cambio radical}

En el país vecino se ha pasado en el último año de poseer un sistema mixto, al estilo del modelo español o el portugués, a una nueva normativa que pretende eliminar la publicidad de la televisión pública. Hasta 2012, cuando el "apagón" será total, no está permitida la presencia de anuncios a partir de las 20 horas. La reducción de los ingresos, estimada en 380 millones de euros anuales, pasa a ser compensada por una tasa del $0,9 \%$ sobre la cifra de negocios de los operadores de telefonía móvil e Internet, además de que las cadenas privadas deberán colaborar por ley con un 1,5\% de su cuota de ingresos por publicidad.

Tras conocer cuál es la situación del mercado publicitario dentro de los países de nuestro alrededor, se podrán entender mejor los contenidos de la nueva ley, en vigor desde el primer día del mes de septiembre, y que pasamos a analizar.

\section{La ley en España}

La televisión pública se ha venido financiando tradicionalmente en España con un sistema mixto que constaba de una subvención pública y unos ingresos comerciales que permitieran lograr un equilibrio presupuestario e impedir la generación de deuda. Esto significaba que la televisión pública debía conseguir en el libre mercado internacional los mejores contenidos posibles para poder competir con las televisiones privadas y no perder audiencia, que es la que atrae la inversión publicitaria y, claro está, el dinero. De no ser así, las cadenas privadas acapararían toda la inversión de los anunciantes y llevaría a que los ingresos comerciales de RTVE fueran menores, teniendo el Estado por tanto, que contribuir con cantidades de dinero mayores a cargo de sus presupuestos. Cada punto menos de audiencia dentro de la televisión pública, en el mercado de la publicidad, iba a parar a las televisiones privadas y viceversa. Eso implica que buena parte de la programación de las televisiones públicas tendría que ser pagada con cargo al presupuesto del Estado, es decir, repercutiendo en el bolsillo de los españoles.

Este extremo no es baladí, pues desde siempre se ha comentado que el concepto de servicio público es el pivote sobre el que gravita la legalidad o no de las medidas tomadas. Así, López VidAles, AzURMENDI y OrTiz (2012: 41) consideran que "este nuevo ordenamiento jurídico redefine cuestiones trascendentales como los principios, criterios y objetivos del servicio público que deben prestar los distintos agentes, refuerza y garantiza su independencia, implanta nuevos instrumentos legales para dotar a las radiotelevisiones públicas de estabilidad y transparencia financiera, así como de eficaces estructuras organizativas y de gestión".

En el caso de las radios públicas, el concepto de servicio público también queda al albur del legislador. Así, los criterios comerciales ceden ante la atención a minorías necesitadas de programación específica. Destaca, no obstante, y en paralelo con Radio Nacional de España, la Cadena COPE como exponente de radio de compromiso con sectores comercialmente menos valiosos. Destaca el trabajo de PEÑA JIMÉNEZ (2012: 24) al que nos remitimos aquí para mayor información desglosada por cadenas. Un ejemplo de este tipo de programas de servicio público sería 'Juntos paso a paso' "programa, cuya audiencia según el Estudio General de Medios, supera los 80.000 oyen- 
tes, tiene como propósito servir de punto de encuentro de estos colectivos, al tiempo que aportar iniciativas que ayuden a la normalización de la vida de los mayores y los discapacitados. Se abordan para ello todas las facetas posibles: accesibilidad, adaptabilidad e integración social y laboral de personas con discapacidad, envejecimiento activo, cultura, legislación, salud, etc”. Este es el espíritu de servicio público que se pretende cuidar con una legislación ex profeso.

Por ello, nos detendremos, párrafo a párrafo, para estudiar cuál es el contenido cualitativo de la nueva ley. Nos centraremos más particularmente en el Preámbulo y en el Capítulo I, por ser aquellos que reflejan la naturaleza de la Ley y los más representativos para nuestro estudio. El lector puede acudir al texto completo en el Boletín Oficial del Estado del día 31 de agosto de 2009.

La filosofía de la nueva ley queda reflejada en el Preámbulo de la misma, además de indicarnos cuál es la finalidad de la nueva ley, adicionando aquí ya el concepto de eliminar la publicidad de RTVE y establecerse en un sistema único de financiación.

Los dos siguientes párrafos se centran en que la Ley se convierte en garante de la universalidad y gratuidad del servicio público que constituye RTVE, proclamando la renuncia de la Corporación a cualquier menoscabo en esos derechos. Igualmente, la Ley, en un párrafo de clara intención pedagógica, exhorta a las operadoras privadas, como beneficiarias de los ingresos publicitarios y por tanto de la decisión de que RTVE no se lucre mediante la emisión de anuncios, a que aporten razonablemente una cantidad para ayudar a mantener a la televisión pública. No debe ser el Estado el que sufrague los gastos o, mejor dicho, la falta de ingresos que va a sufrir, a partir de la entrada en vigor de esta ley, la Corporación estatal. Aquí se muestra cierta ambigüedad, al no especificarse esta aportación "razonable", ni en cantidades brutas ni en porcentajes.

El Capítulo $1^{\circ}$ de la nueva legislación es muy importante, ya que versa sobre el objeto de la misma, en un primer artículo; y sobre la nueva financiación que va a pasar a tener RTVE, en su segundo y último artículo.

"Artículo 1. Objeto.

La presente ley tiene por objeto regular el sistema de financiación de la Corporación de Radio y Televisión Española y de sus filiales prestadoras del servicio público de radio y televisión de titularidad del Estado".

El título del artículo ya nos muestra perfectamente cuál va a ser el contenido de la ley y el porqué de la necesidad de la misma. La ley regulará el sistema de financiación de la Corporación de Radio y Televisión Española y de sus filiales. Este será el cometido de la Ley.

El artículo 1 viene a legislar lo que ya se ha explicado en el texto del Preámbulo, marcando la naturaleza de lo que será el resto del texto. El Artículo 2 está enfocado sobre las distintas fuentes de financiación que pasa a tener la Corporación Radio Televisión Española. El nuevo modelo prevé que TVE deje de emitir publicidad, ya que no aparece en ninguno de los puntos del artículo, como vía de financiación. En este texto se remite a los Presupuestos Generales del Estado para conocer cuáles son las compensaciones por el cumplimiento de las obligaciones de servicio público. En estos 
Presupuestos es donde se muestra cuál es el porcentaje de beneficios que cada operador favorecido por los cambios en la financiación de la Corporación (es decir, la eliminación de la competencia publicitaria) debe aportar. Textualmente se dispone que las televisiones privadas pasarán a colaborar con un 3\% sobre los ingresos publicitarios que obtengan; los operadores de pago aportarán un 1,5\% y los operadores de telecomunicaciones un $0,9 \%$ de sus retribuciones por publicidad, algo muy similar al caso francés.

Entre otras aportaciones, RTVE también recibirá un porcentaje sobre el rendimiento de la tasa sobre reserva del dominio público radioeléctrico, los operadores de telecomunicaciones y los beneficios íntegros derivados de la venta de productos y rentas de su patrimonio, además de las aportaciones voluntarias que reciba la Corporación RTVE por parte de otras personas o instituciones. Es decir, se instituye RTVE, si no como dueña, sí como usufructuaria de los derechos del espectro radioeléctrico estatal. Algo similar a lo que aconteció con el monopolio de Telefónica.

El segundo apartado de este Artículo 2 constituye un fidedigno elemento de seguridad que garantiza que RTVE va a mantener una financiación adecuada, a pesar de que se produjera una hipotética disminución de los ingresos obtenidos ya sea a través del dominio público radioeléctrico, ya de los operadores de telecomunicaciones o ya sea de las sociedades prestadoras y concesionarias del servicio de televisión. Se refiere al Capítulo IV, en el que en su artículo 8 se indica: "la Corporación RTVE constituirá un fondo de reserva que estará dotado con los ingresos que superen el coste neto del servicio público prestado en el correspondiente ejercicio presupuestario"

En caso de que ese fondo de reserva no fuera capaz de cumplir con los presupuestos necesarios para el correcto funcionamiento de los ejercicios y obligaciones del Ente público, por una reducción de los ingresos mencionados en los diferentes puntos del artículo, el presupuesto se contemplará con fondos regulares de los Presupuestos Generales del Estado, siempre y cuando no se haya sobrepasado el límite de gasto de la Corporación, que se encuentra fijado en el Artículo 3 "Límites de la financiación y dimensión económica de la Corporación RTVE".

En esta ley no se plantean los horarios de especial protección a la infancia, pero creemos que supone una ocasión perdida ya que se trata de un servicio público el prestado, con su responsabilidad inherente, más allá de criterios crematísticos. Se producen excesivos casos diariamente de lo que Maribel MARTínEz EDER ha analizado desde sus artículos:

"Cuando un niño en España se pone delante del televisor, por ejemplo a la vuelta del colegio, por supuesto en horarios de protección e incluso en los súper protegidos, hallará, con toda probabilidad, contenidos inadecuados e indeseables, televisión basura y ni la mínima referencia cultural. Además, salvo excepción, no encontrará ninguna programación dedicada precisamente a la infancia, ámbito dejado de la mano de Dios por las productoras y responsables de contenidos desde tiempo inmemorial" (MARTínez EDER, 2008: web).

\section{Reacciones a la ley}

Una ley no es sólo texto, sino espíritu. Las respuestas a la nueva ley por parte de diversos sectores no se han hecho esperar desde que la Vicepresidenta Primera de Go- 
bierno, María Teresa Fernández De la Vega, manifestara su intención de reformar la Ley de Financiación y, más si cabe, desde que se conoció el contenido de la nueva ley y sus repercusiones.

Las reacciones al texto se han producido desde muy diversos sectores, cubriendo prácticamente todo el espectro de públicos de la Corporación RTVE. Ya en la tramitación de la ley el gobierno recibió duras críticas por parte de los grupos del Congreso, salvando las enmiendas a la totalidad de la misma, gracias a la abstención del principal grupo de la oposición, el Partido Popular, y al apoyo recibido por parte de los escaños de Convergència i Unió (CiU). El resultado final de las votaciones de estas enmiendas a la totalidad fue 173 votos en contra, frente a 150 abstenciones y 13 votos a favor.

El diputado del Partido Nacionalista Vasco (PNV) José Ramón Beloki criticó que la medida legislativa. El diputado vasco recordó que el modelo francés en el que se basa "ha fracasado" y ha pedido la devolución del proyecto al Gobierno. Por su parte, el portavoz del Bloque Nacionalista Galego (BNG) en el Congreso, Francisco Jorquera anunció su negativa a la ley y el riesgo de que fuera modelo para las autonómicas. Por otro lado, la diputada por 'Unión, Pueblo y Democracia', Rosa Díez, criticó el hecho de que esta ley ponía en riesgo el modelo de utilidad pública de RTVE.

Desde la patronal de los canales de televisión privados, $\mathrm{UTECA}^{1}$, se ha condenado el hecho de que RTVE haya contratado publicidad hasta final de año pese a que la ley que elimina la publicidad en los canales públicos estatales haya sido aprobada en las Cortes ya en el pasado mes de julio. El organismo aduce que los responsables de la Corporación "han pisado la frontera del fraude de ley, puesto en mal lugar al Gobierno y al poder legislativo".

La crítica que le hace UTECA a la nueva ley en vigor desde septiembre es que RTVE va a poder emitir publicidad hasta el mes de diciembre, presuntamente, para cumplir con las campañas vendidas con antelación. Desde UTECA se aduce que no se deberían haber firmado acuerdos publicitarios conociendo que la nueva ley se encontraba en proceso. UTECA protesta por el sistema de financiación mixto de RTVE, pero si estudiamos los datos de la Comisión del Mercado de las Telecomunicaciones (2008), observamos hitos ciertamente sorprendentes:

\begin{tabular}{|cl|c|c|c|}
\hline \multicolumn{2}{|c|}{ AÑO } & $\mathbf{2 0 0 7}$ & $\mathbf{2 0 0 8}$ & VARIACIÓN \\
\hline & \multicolumn{3}{|c|}{ Minut os a ire } \\
\hline E & Telecinco & 221.725 & 343.965 & $55,10 \%$ \\
\hline Ancinco & Antena 3 & 165.032 & 188.779 & $14,40 \%$ \\
\hline reVe & RTVE & 273.092 & 279.795 & $2,50 \%$ \\
\hline
\end{tabular}

${ }^{1}$ UTECA: Unión de las Televisiones Comerciales Asociadas. Patronal de los operadores de televisión privados que actúan en nuestro país. 


\begin{tabular}{|c|c|c|c|c|}
\hline \multicolumn{2}{|c|}{ AÑO } & 2007 & 2008 & VARIACIÓN \\
\hline & & \multicolumn{3}{|c|}{ Minutos aire } \\
\hline cuatro ${ }^{\circ}$ & Cuatro & 86.937 & 76.827 & $-11,60 \%$ \\
\hline & TV3 & 118.317 & 75.975 & $-35,80 \%$ \\
\hline & La Sexta & 125.644 & 283.618 & $125,70 \%$ \\
\hline & TeleMadrid & 77.593 & 57.276 & $-26,20 \%$ \\
\hline & Canal Sur & 143.862 & 99.052 & $-31,10 \%$ \\
\hline Se & ЕTB & 98.306 & 128.201 & $30,40 \%$ \\
\hline & Canal 9 & 76.722 & 72.492 & $-5,50 \%$ \\
\hline & TVG & 81.748 & 77.788 & $-4,80 \%$ \\
\hline VEOT & Veo TV & 97.263 & 376.498 & $287,10 \%$ \\
\hline NET TV & Net TV & 97.263 & 131.327 & $35,00 \%$ \\
\hline
\end{tabular}

Datos extraídos de la Comisión del Mercado de las Telecomunicaciones (2008)

Todos los canales de televisión de titularidad privada, excepto Cuatro, han aumentado, en el último ejercicio estudiado, la cantidad de minutos de aire, frente a $R T V E$, que ha elevado su tiempo de emisión destinado a anuncios en un $2,5 \%$, siendo de entre las cadenas de televisión más seguidas, la que menor porcentaje de aumento de la actividad publicitaria ha experimentado. Desde UTECA, pese a venir vulnerando sistemáticamente la regulación en cuanto al tiempo máximo de publicidad se refiere, incluso aumentando los minutos de aire (que incluyen los minutos de anuncios, autopromoción y Teletienda) de un ejercicio a otro, paradójicamente critican a la televisión pública en cuanto a emisión publicitaria. Desde el sector de las telecomunicaciones, uno de los principales implicados en la nueva Ley de Financiación de la Corporación RTVE, también se han formulado críticas a la ley.

La Asociación de Empresas Operadoras y de Servicios de Telecomunicaciones (ASTEL), que incluye a 16 de las principales operadoras de telecomunicaciones e Internet, expuso ante el Consejo de Estado ciertas alegaciones en contra de la aportación económica a RTVE, que se centraban en su carácter excluyente frente a algunos medios. ASTEL subrayaba que es contradictorio que empresas de sectores que "con toda seguridad van a verse claramente beneficiadas", refiriéndose a las emisoras de radio, 
queden eximidas del deber de realizar aportaciones económicas, mientras que desde el sector de las telecomunicaciones, sí que se deben abonar.

Una de las organizaciones de operadores de telecomunicación, la Asociación de Empresas de Tecnologías de la Información y Comunicaciones de España (AETIC), ha advertido que quizá sea necesario subir las tarifas para el uso del teléfono e Internet en el caso de tener que colaborar en la financiación de TVE, para seguir asegurando su rentabilidad, por lo que el público volvería a financiar TVE no sólo desde sus impuestos, si la recaudación es insuficiente, sino también desde un nuevo canon comercial. AETIC afirma que el porcentaje con el que participará en el nuevo modelo de financiación de la televisión pública es excesivo, ya que según sus cálculos, estará obligada a aportar casi la mitad de la financiación de la cadena pública, "un $41 \%$ en total". De igual modo, soportará el $74 \%$ de las tasas abonadas entre las televisiones privadas y las operadoras de telecomunicaciones, debido a la adición de los 290 millones de euros por el $0,9 \%$ a los 213 millones de euros por el uso del espectro radioeléctrico. La asociación alertó de que las tasas específicas para los operadores de telecomunicación carecían de sentido, ya que este sector soporta "una carga importante de impuestos especiales". Se refiere a tributos exclusivos en nuestro país, como los de telefonía impuestos por el Gobierno del Estado o los impuestos medioambientales.

Desde el sector publicitario también ha habido declaraciones de tono disconforme respecto a la ley. Entre ellas, destaca el "Manifiesto del sector publicitario en contra de la Ley de Financiación de RTVE". Una representación de los damnificados por la ley (compuesta por consumidores, fabricantes, industria de la publicidad) manifiesta su rechazo a dicha Ley, ya que considera que no beneficia al tejido productivo del país, al perjudicar el consumo y crear paro. Protestan porque la ley no ha tenido en consideración a los estamentos anteriormente citados, porque no recoge las recomendaciones del Consejo de Estado ni de la CMT, y porque se efectúa innecesariamente por trámite de urgencia, sin analizar realmente los graves efectos económicos que va a producir. Opinan que hay 18.000 empleos en peligro, y 42 millones de ciudadanos que van a soportar el aumento de costes, costes que ahora corrían a cargo de las empresas anunciantes y que no suponían un aumento del canon ni nuevas cargas sobre el erario público. Además, según las asociaciones firmantes, esta ley afectará de forma muy negativa a las 1.350 PYMES, frente a las 4.637 empresas medianas y grandes, ya que estas primeras no podrán asumir el aumento de precios, y que se quedarán sin acceso a la publicidad local en televisión al desaparecer las desconexiones regionales de TVE. Así, este Manifiesto sostiene que la nueva ley "estigmatiza" a la publicidad al considerar que es positivo para la sociedad la eliminación de la misma en TVE y no la saturación de la publicidad.

Este Manifiesto lo firmaron quince asociaciones, entre las que destacan la Asociación de Agencias de Medios (AM); la Asociación Española de Agencias de Publicidad (AEAP); la Asociación Española de Anunciantes (AEA); o la International Advertising Association (IAA). 


\section{Conclusiones}

La ley de Financiación de la Corporación de RTVE, que entró en vigor el 1 de septiembre de 2010, ha supuesto un giro radical en el panorama audiovisual español. El cambio en la financiación de la Corporación pública ha venido siendo una constante en las reclamaciones de las televisiones privadas de España desde hace varios años.

A pesar de la rentabilidad de los operadores de titularidad privada, que solamente se ha resentido durante la crisis global que están sufriendo España y Europa, desde los grupos empresariales que rigen las políticas de las televisiones privadas, se ha venido demandando la supresión de la publicidad en la televisión pública, aduciendo una supuesta "competencia desleal" por parte del Ente estatal.

Desde las televisiones privadas se ha protestado encarecidamente por la competencia que TVE suponía en la contratación y adquisición de productos televisivos, tales como eventos deportivos o cine, encareciendo los precios al no tener la necesidad de obtener superávit en sus ejercicios ya que la Corporación se encuentra respaldada por los Presupuestos Generales del Estado.

Además existe una corriente de opinión crítica con la televisión pública nacional y su sistema de financiación actual derivado de la ley, mostrándose más favorable al sistema de la BBC británica.

Cabe recordar que estas televisiones de titularidad privada adquieren también un compromiso de servicio público en cuanto que reciben una licencia de emisión por parte del Estado; y unas obligaciones morales que se muestran en el Código de Autorregulación y que se han venido vulnerando sistemáticamente, especialmente en lo que se refiere a las responsabilidades para con los menores, que les debería hacer reflexionar sobre su papel en la sociedad actual, por no hablar de la vulneración de la Ley de Máximos de Tiempo de Emisión Publicitaria.

Se podría considerar como un punto vacuo, en esta ley, el hecho de que no afronte directamente el papel que deben desempeñar las televisiones privadas en lo referido a 'su servicio social'. Así pues, coincidimos con lo dispuesto por el profesor Enrique CAstelló Mayo:

"No se trata en absoluto de una cuestión baladí, en la medida en que, en el extremo, dicho planteamiento invalida la propia existencia como tal del concepto mismo de 'medios' de comunicación: pues dichas instituciones, más que limitarse a una simple labor transmisora, difusora o mediadora entre determinados sucesos y los sujetos receptores, producen masiva e incesantemente la realidad social". (CASTELló MAYO, 2003: web)

La reflexión del profesor Lorenzo Díaz titulado "Autopsia a la caja sucia” ilustra este sentir. En él se lee:

"De canguro catódico a acompañante del abuelo: La televisión ha ido usurpando el papel de otros grupos en el llamado proceso de socialización del individuo. Es el canguro catódico, el pariente que nunca falla, el que acompaña al anciano en su soledad. Ocupa el terreno dejado por otras instituciones sociales (familia, escuela, Estado) y lo hace extendiendo y trivializando el campo del saber, sustituyendo un saber humanista por una especie de saber hacer, saber práctico; en suma, un saber mosaico muy representativo de la 
cultura de masas [...]. La televisión se impone como una gran casa de citas en la que todos cabemos y donde exhiben su levedad los seres menos relevantes, monstruos mediáticos de todo a cien, personajes kleenex, los que con el mínimo esfuerzo se han hecho con la caja y la popularidad" (DíAz, 2004: web).

Las presiones recibidas desde los principales grupos de comunicación, así como las exigencias por parte de las instituciones comunitarias, han llevado al Gobierno a tramitar una ley que ha resultado muy polémica y que ha sido vilipendiada desde diversos sectores de la sociedad, pues supone el fin de un sistema de financiación que, desde el lado positivo, le produjo cuantiosos beneficios, permitiendo su crecimiento tanto cuantitativo como cualitativo a lo largo de su historia, ya que no existía competencia en el mercado publicitario, lo cual mejoró su inicial situación que otra hubiera sido si sólo se hubiera visto respaldada únicamente con las aportaciones estatales.

La ley ha pretendido emular a la televisión británica en cuanto a la ausencia de publicidad para la financiación, siguiendo el ejemplo de la televisión pública francesa, que recientemente había reducido drásticamente la publicidad, tratando de eliminarla totalmente a partir de 2012, aunque siendo menos permisiva con los plazos, ya que es en 2010 cuando el "apagón" publicitario ha sido total. Así mientras, en Francia la publicidad no es permitida a partir de las 20:00 h., como en el modelo alemán, en la televisión estatal española se mantendrán los límites actuales para que TVE pueda cumplir con los compromisos comerciales pactados anteriormente a que la ley entrara en vigor.

Las críticas a la ley han llegado desde todos los públicos afectados, y se han referido tanto a la manera de tramitarla, con un carácter de urgencia que desde ciertos grupos se ha considerado innecesario, como al contenido de la ley, del que desde algunos sectores se ha catalogado de injusto y que puede suponer el fin de los contenidos de calidad en la televisión pública y una pérdida de rentabilidad en los nuevos sustentadores de la financiación de TVE que va a llevar a la pérdida de empleo de muchos trabajadores, si los vates apocalípticos tienen razón en sus postulados. El tiempo nos dirá si este objetivo se cumple o, contrariamente, como las perspectivas más alarmistas afirman, este nuevo sistema de financiación puede suponer el final de la televisión pública en España tal y como la conocemos. Lo único que parece claro, en todo este entramado, es que las cadenas de titularidad privada y los demás soportes publicitarios van a verse beneficiados con la marcha de uno de los principales rivales en el reparto del "pastel" publicitario.

\section{Referencias bibliográficas}

BOLETÍN OFICIAL DEL ESTADO (2009): 31 de agosto Disponible desde Internet en: www.boe.es/boe/dias/2009/08/31/pdfs/BOE-A-2009-13988.pdf [acceso el 1511-2011] Madrid, Ministerio de la Presidencia.

CASTELLÓ, Enrique (2003): "La producción del presente social en televisión” Revista Científica de Información y Comunicación, ${ }^{\circ}$ 1, pp. 85-94. 
COMISIÓN DEL MERCADO DE LAS TELECOMUNICACIONES (2008): “Informe anual 2008". pp. 118-135. Disponible desde Internet en: www.cmt.es/cmt ptl_ext/SelectOption.do?nav=publi_anuales\&detalles $=09002719800868 \mathrm{c} 6 \&$ pagina $=1$ [acceso el 15-01-2012]

DÍAZ, Lorenzo (2004): “Autopsia a la caja sucia” en Vivat Academia, n 59. Octubre Disponible desde Internet en: http://www.seeci.net/vivataca/anteriores/n59/Num59 /PDFs/n59-3.pdf [acceso el 25-09-2011]

ESPINOSA, Ruth (2009): "Los operadores anuncian subidas de precios si les obligan a financiar RTVE", $A B C, 8$ de mayo.

GÓMEZ, Rosario (2009): "La ley de financiación de TVE limitará su acceso a contenidos de deporte y cine", El País. 5 de mayo.

LÓPEZ VIDALES, Nereida; AZURMENDI ADARRAGA, Ana \& ORTIZ SOBRINO, Miguel Ángel (2012): "Hacia un nuevo marco regulatorio y de gestión de la televisión pública en España: El bienio del cambio" en Revista de la SEECI, $\mathrm{n}^{\circ}$ 27, Marzo. Disponible desde Internet en: www.ucm.es/info/seeci/Numeros/Numero\%2027/Varios3.pdf [acceso el 25-03-2012]

MARTÍNEZ EDER, Maribel (2008): "La sociedad de la información y el derecho de los menores", en Vivat Academia n ${ }^{\circ}$ 93, Marzo http://www.seeci.net/vivataca/anteriores/n93/Num93/PDFs/n93.pdf [acceso el 02-10-2011]

MINISTERIO DE EDUCACIÓN Y CIENCIA (2010): Historia de la Televisión en España. Disponible desde Internet en: http://recursos.cnice.mec.es/media/television/bloque2/index.html\# [acceso el 15-02-2012]

PEÑA JIMÉNEZ, Palma (2012): "La radio social y de servicio en España: el ejemplo de 'Juntos paso a paso' de Radio Nacional de España” en Revista de la SEECI n ${ }^{\circ}$ 27, Marzo. Disponible desde Internet en: www.ucm.es/info/seeci/Numeros/Numero\%2027/Palma.pdf [acceso el 02-04-2012]

VV.AA. (2009): "18.000 empleos en peligro ante la eliminación de publicidad en TVE", El Mundo. 15 de junio.

VV.AA. (2009): "Astel rechaza la propuesta de crear una tasa a operadores para financiar la televisión pública", El Economista. 14 de abril.

VV.AA. (2009): "El Gobierno prevé eliminar la publicidad en TVE en septiembre", El País, 4 de mayo.

VV.AA. (2009): "La financiación de las teles públicas en Europa", El Periódico.15 de abril.

VV.AA. (2009): "Las privadas acusan a TVE de estar al límite legal con la publicidad", La Vanguardia 9 de septiembre. 